\title{
A comparison of three second-generation swirl-venturi lean direct injection combustor concepts
}

\author{
Kathleen M. Tacina, Derek P. Podboy, and Zhuohui Joe He* \\ NASA Glenn Research Center, Cleveland, Ohio, 44135 \\ Phil Lee ${ }^{\dagger}$ and Bidhan Dam ${ }^{\ddagger}$ \\ Woodard FST, Zeeland, Michigan, 49464 \\ Hukam Mongia § \\ Purdue University, West Lafayette, Indiana, 47907
}

\begin{abstract}
Three variations of a low emissions aircraft gas turbine engine combustion concept were developed and tested. The concept is a second generation swirl-venturi lean direct injection (SV-LDI) concept. LDI is a lean-burn combustion concept in which the fuel is injected directly into the flame zone. All three variations were based on the baseline 9point SV-LDI configuration reported previously. ${ }^{1}$ The three second generation SV-LDI variations are called the 5-recess configuration, the flat dome configuration, and the 9recess configuration. These three configurations were tested in a NASA Glenn Research Center medium pressure flametube. All three second generation variations had better low power operability than the baseline 9-point configuration. All three configurations had low $\mathrm{NO}_{\mathrm{x}}$ emissions, with the 5-recess configuration generally having slightly lower $\mathrm{NO}_{\mathrm{x}}$ than the flat dome or 9-recess configurations. Due to the limitations of the flametube that prevented testing at pressures above $20 \mathrm{~atm}$, correlation equations were developed for the flat dome and 9-recess configurations so that the landing-takeoff $\mathrm{NO}_{\mathrm{x}}$ emissions could be estimated. The flat dome and 9-recess landing-takeoff $\mathrm{NO}_{\mathrm{x}}$ emissions are estimated to be 81-88\% below the CAEP/6 standards, exceeding the project goal of $75 \%$ reduction.
\end{abstract}

\section{Introduction}

One major focus of NASA's aeronautics programs is to reduce emissions of the oxides of nitrogen, $\mathrm{NO}_{\mathrm{x}}$. The recently-concluded Environmentally Responsible Aviation (ERA) project focused on reducing $\mathrm{NO}_{\mathrm{x}}$ emissions from large-core engines. The ongoing Advanced Air Transport Technology (AATT) project is focused on reducing $\mathrm{NO}_{\mathrm{x}}$ emissions from small-core engines.

Although ERA and AATT focus on different size engines, some low- $\mathrm{NO}_{\mathrm{x}}$ combustor concepts developed under ERA are applicable to AATT. This paper describes one such concept: swirl-venturi (SV) lean direct injection (LDI). LDI is a fuel-lean combustor concept. In other words, LDI is fuel-lean throughout the combustion zone. All air except that used for liner cooling enters through the dome.

To minimize $\mathrm{NO}_{\mathrm{x}}$ emissions, LDI must avoid local near-stoichiometric regions. This requires rapid and uniform fuel-air mixing. To promote this mixing, multiple small fuel-air mixers replace one conventionallysized fuel-air mixer. Each fuel-air mixer is relatively simple, with a single fuel injection point.

Three variations of SV-LDI were developed under ERA by Woodward, FST. Two of these variations were tested under ERA at large-core engine cycle conditions. The third was tested under AATT at small-core cycle conditions.

\footnotetext{
*Aerospace Engineer, Combustion Branch

$\dagger$ Engineer, AIAA member

$\ddagger$ Engineer

$\S$ Visiting Professor, School of Mechanical Engineering, AIAA Fellow
} 


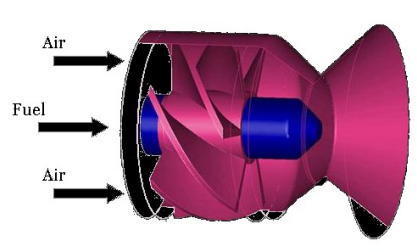

(a)

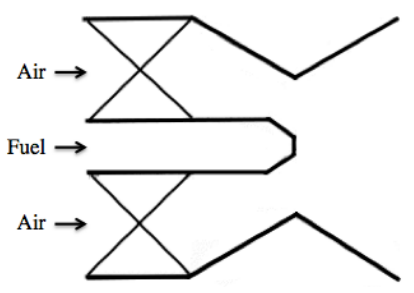

(b)

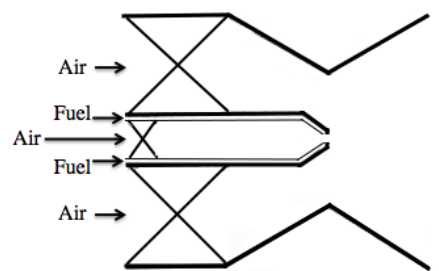

(c)

Figure 1: Illustrations of a single SV-LDI fuel-air mixer: (a) isometric drawing with a simplex fuel injector, (b) sketch with a simplex fuel injector, (c) sketch with an airblast fuel injector.

This paper presents emissions results from the NASA Glenn flametube testing of the three secondgeneration LDI configurations. Since $\mathrm{NO}_{\mathrm{x}}$ emissions from the 5-recess and flat dome configurations have been previously reported, ${ }^{2}$ this paper focuses on the 9-recess configuration.

\section{Hardware and Experimental Facilities}

\section{A. LDI-2 Hardware}

In LDI, multiple small fuel-air mixers replace one traditionally-sized fuel-air mixer. Each of the fuel-air mixers in LDI is relatively simple. As shown in Fig. 1a, a single swirl-venturi LDI (SV-LDI) fuel-air mixer consists of a fuel injector and an air passage with an axial air swirler followed by a converging-diverging venturi section. The fuel injector is inserted through the center of the air swirler, with the tip typically located at the venturi throat.

In the first-generation SV-LDI, each fuel-air mixer was identical or nearly-identical, with only two variations. First, the swirler vane angles could be varied; typical vane angles were $45^{\circ}$ or $60^{\circ}$. Second, the fuel-air mixers were split into multiple fuel circuits to investigate fuel staging. ${ }^{1,3,4}$

First-generation SV-LDI successfully reduced $\mathrm{NO}_{\mathrm{x}}$ emissions at cruise and high-power conditions, but had poor operability at low power. Therefore, second-generation SV-LDI was developed. Second-generation SVLDI is based upon the first-generation concept, but includes advanced features designed to further reduce $\mathrm{NO}_{\mathrm{x}}$ emissions and improve low power operation. These advanced features in second-generation SV-LDI introduce three additional variations into the fuel-air mixer design. First, the size of each fuel-air mixer can be small or large. Second, the fuel-air mixers can be recessed from the dome or not recessed. Third, the type of fuel injector can be either simplex (like all first-generation LDI fuel-air mixers) or airblast.

Second-generation SV-LDI configurations have four fuel circuits, called stages: a pilot stage and three main stages, main-1, main-2, and main-3. Within each stage, all fuel-air mixers are identical. The pilot stage has a single large fuel-air mixer and each main stage has four small fuel-air mixers.

Three second-generation SV-LDI configurations were tested. Each of these configurations had a 114-mm by 114-mm square cross-sectional area. These configurations are named for the number of fuel-air mixers that are recessed: for the flat dome configuration, no fuel-air mixers are recessed; for the 5-recess, the pilot and the four main-1 fuel-air mixers are recessed; and for the 9-recess, the pilot, the four main-1, and the four main-2 fuel-air mixers are recessed. These configurations are shown in Figure 2, with each stage labeled. The fuel injector types and swirler angles for each stage of each configuration are given in Table 1.

During the flat dome and 5-recess testing, only three separate fuel circuits were supported. This required ganging together the fuel lines for two stages. For the flat dome testing, the fuel lines for the main 2 and main 3 stages were fed from the same circuit. Since the air path and the flow numbers were similar for main 2 and main 3, the local fuel-air ratio was the same for the main 2 and main 3 stages. In contrast, for the 5-recess testing, the pilot and main 2 stages were fed from the same circuit. These stages were dissimilar in both air path and flow number; as a result, local fuel-air ratio of the pilot stage was always higher than that of the main 2 stage.

For the 9-recess testing, each stage had a separate fuel circuit. 
Table 1: Second Generation SV-LDI configurations. For each stage, the table gives the type of fuel injector and the air swirler angle(s). (OAS: outer air swirler, IAS: inner air swirler, cw=clockwise, ccw=counterclockwise)

\begin{tabular}{|c|c|c|c|c|c|c|c|c|}
\hline Configuration & $\begin{array}{c}\text { Pilot } \\
\text { Injector }\end{array}$ & $\begin{array}{c}\text { Pilot } \\
\text { Swirler }\end{array}$ & $\begin{array}{l}\text { Main } 1 \\
\text { Injector }\end{array}$ & $\begin{array}{l}\text { Main } 1 \\
\text { Swirler }\end{array}$ & $\begin{array}{l}\text { Main } 2 \\
\text { Injector }\end{array}$ & $\begin{array}{l}\text { Main } 2 \\
\text { Swirler }\end{array}$ & $\begin{array}{l}\text { Main } 3 \\
\text { Injector }\end{array}$ & $\begin{array}{l}\text { Main } 3 \\
\text { Swirler }\end{array}$ \\
\hline Flat Dome & Simplex & $55^{\circ} \mathrm{ccw}$ & Simplex & $45^{\circ} \mathrm{ccw}$ & Airblast & $\begin{array}{l}\text { IAS: } 45^{\circ} \mathrm{cw} \\
\text { OAS: } 45^{\circ} \mathrm{cw}\end{array}$ & Airblast & $\begin{array}{l}\text { IAS: } 45^{\circ} \mathrm{cw} \\
\text { OAS: } 45^{\circ} \mathrm{cw}\end{array}$ \\
\hline 5-Recess & Airblast & $\begin{array}{l}\text { IAS: } 57^{\circ} \mathrm{cw} \\
\text { OAS: } 57^{\circ} \mathrm{ccw}\end{array}$ & Simplex & $45^{\circ} \mathrm{cw}$ & Airblast & $\begin{array}{l}\text { IAS: } 45^{\circ} \mathrm{cw} \\
\text { OAS: } 45^{\circ} \mathrm{ccw}\end{array}$ & Airblast & $\begin{array}{l}\text { IAS: } 45^{\circ} \mathrm{cw} \\
\text { OAS: } 45^{\circ} \mathrm{ccw}\end{array}$ \\
\hline 9-Recess & Airblast & $\begin{array}{l}\text { IAS: } 57^{\circ} \mathrm{cw} \\
\text { OAS: } 57^{\circ} \mathrm{ccw}\end{array}$ & Simplex & $45^{\circ} \mathrm{ccw}$ & Airblast & $\begin{array}{l}\text { IAS: } 45^{\circ} \mathrm{cw} \\
\text { OAS: } 45^{\circ} \mathrm{cw}\end{array}$ & Airblast & $\begin{array}{l}\text { IAS: } 45^{\circ} \mathrm{cw} \\
\text { OAS: } 45^{\circ} \mathrm{cw}\end{array}$ \\
\hline
\end{tabular}

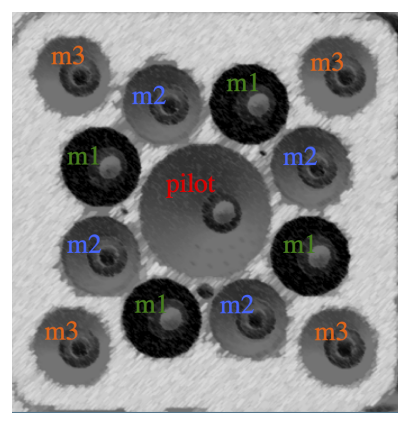

(a)

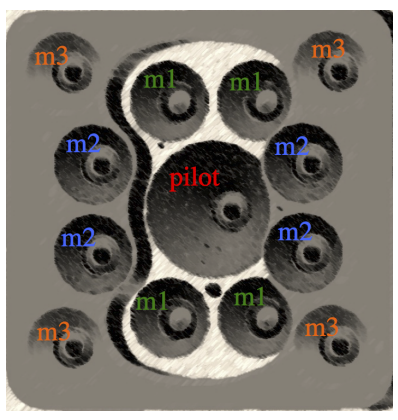

(b)

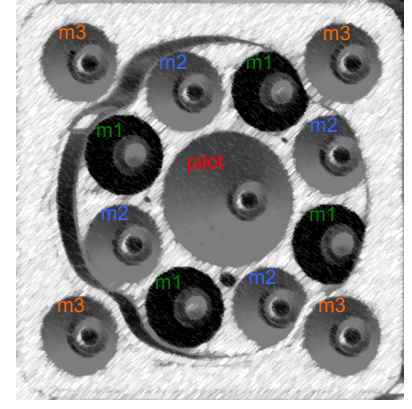

(c)

Figure 2: Second generation SV-LDI hardware: (a) flat dome, (b) 5-recess, and (c) 9-recess configurations.

\section{B. CE-5 Medium Pressure Flametube}

These tests were done in the CE-5 intermediate pressure combustion facility flametube at NASA Glenn Research Center. A sketch of a flametube is shown in Fig. 3. The flametube has a cast ceramic liner. This facility can supply nonvitiated air preheated to $1200 \mathrm{~F}$ at pressures up to 275 psia. The test rig is designed to support up to three fuel circuits; however, additional hardware was added to the 9-recess test, allowing four fuel circuits to be supported.

Steady-state data was acquired at a rate of $1 \mathrm{~Hz}$ using the NASA Glenn ESCORT real-time data acquisition system. It recorded facility conditions such as temperature and pressure as well as gaseous emissions.

Gaseous emissions were measured using a 5-hole probe connected to a gas bench, which followed the SAE ARP-1255D ${ }^{5}$ standard. Post-processing followed the SAE ARP-1533B ${ }^{6}$ standard. Adiabatic flame temperatures are calculated using the Chemical Equilibrium for Applications (CEA) equilibrium code. ${ }^{7,8}$

The equivalence ratio $\phi$ calculated from the gas analysis results was compared to the equivalence ratio calculated from the metered fuel and air flow rates. Unless otherwise noted, only results from stabilized points are shown. For stabilized points, the equivalence ratios calculated by both methods are close, typically within $5 \%$.

Combustion dynamics were measured using dynamic pressure sensors. Dynamic pressure fluctuations were recorded using a Data Translation DT9841-sb high speed data acquisition system. Dynamic pressure fluctuations were typically small; they are described more fully in Tacina et al. ${ }^{9}$

\section{Testing Strategy}

Testing parameters were varied as systematically as was possible with the limited testing time and facility capabilities. Much testing was done at four inlet temperatures: $535 \mathrm{~K}(500 \mathrm{~F}), 650 \mathrm{~K}(700 \mathrm{~F}), 755 \mathrm{~K}(900$ $\mathrm{F})$, and the maximum normal operating temperature $825 \mathrm{~K}(1020 \mathrm{~F})$. At each of these inlet temperatures, 


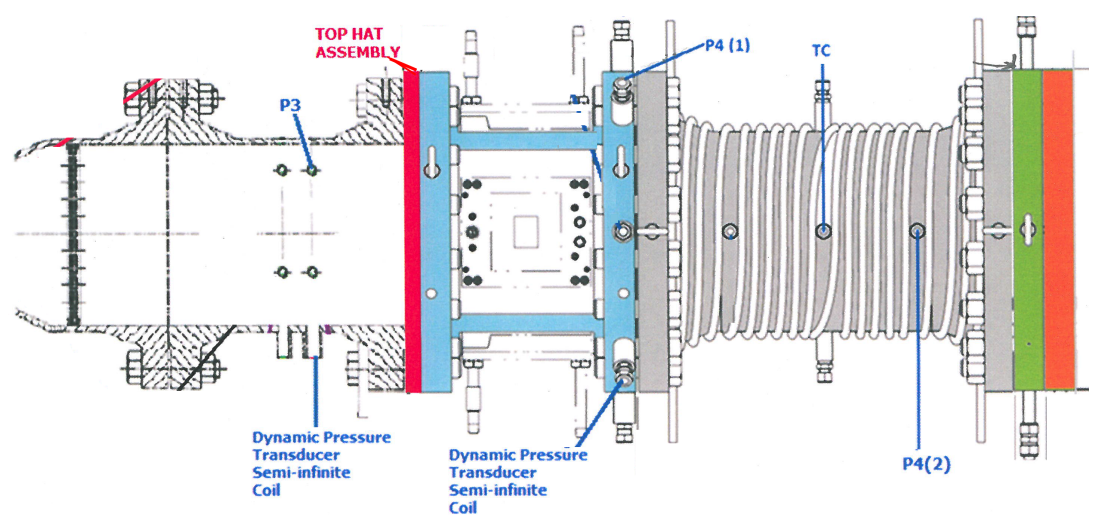

Figure 3: The flametube used for testing the second generation SV-LDI configurations.

Table 2: $N A S A N+3$ small-core cycle, giving the combustor inlet pressure $p_{3}$, combustor inlet temperature $T_{3}$, and combustor equivalence ratio $\phi_{\text {eng. }}$. Twenty percent combustor liner cooling is assumed to calculate the flametube equivalence ratio $\phi_{f t}$ and flametube combusted gas temperature $T_{f t}$

\begin{tabular}{l|ccccr}
\hline Condition & $\begin{array}{c}\mathrm{p}_{3} \\
(\mathrm{MPa})\end{array}$ & $\begin{array}{c}\mathrm{T}_{3} \\
(\mathrm{~K})\end{array}$ & $\phi_{\mathrm{eng}}$ & $\phi_{\mathrm{ft}}$ & $\begin{array}{r}\mathrm{T}_{\mathrm{ft}} \\
(\mathrm{K})\end{array}$ \\
\hline $7 \%$ ICAO & 0.71 & 553 & 0.103 & 0.128 & 890 \\
$30 \%$ ICAO & 1.41 & 661 & 0.186 & 0.233 & 1,231 \\
$85 \%$ ICAO & 3.28 & 835 & 0.325 & 0.402 & 1,727 \\
$100 \%$ ICAO & 3.80 & 870 & 0.354 & 0.442 & 1,832 \\
Cruise & 1.83 & 827 & 0.392 & 0.490 & 1,887 \\
Top of Climb & 1.95 & 834 & 0.377 & 0.471 & 1,858 \\
Rolling Takeoff & 4.43 & 957 & 0.446 & 0.558 & 2,107 \\
\hline
\end{tabular}

we tested at three inlet pressures. At lower inlet temperatures, corresponding to lower inlet pressures, the lowest inlet pressure was $0.7 \mathrm{MPa}$ (100 psia); at higher inlet temperatures, it was $1.0 \mathrm{MPa}$ (150 psia). Some data was also taken at the maximum operating pressure of $1.8 \mathrm{MPa}(260 \mathrm{psia})$ at a temperature slightly below the maximum (1000 F instead of $1020 \mathrm{~F}$ ). In addition, during the flat dome testing we were able to increase the maximum operating temperature to $860 \mathrm{~K}(1090 \mathrm{~F})$ at the cost of reducing the maximum pressure. During the 9-recess testing, we were able to further increase the maximum operating temperature to $1200 \mathrm{~F}$ due to facility upgrades.

In addition, all three configurations were evaluated at the (proprietary) Pratt and Whitney (PW) ERA $\mathrm{N}+2$ cycle conditions. The 9-recess configuration was also evaluated at the NASA N+3 small core cycle conditions; this cycle is given in Table 2. Since testing was done in a ceramic-lined flametube, the flametube equivalence ratio was adjusted for liner cooling. Twenty percent liner cooling was assumed, so the overall combustor equivalence ratio $\left(\phi_{\text {eng }}\right)$ was divided by 0.8 to get the flametube equivalence ratio $\left(\phi_{\mathrm{ft}}\right)$.

\section{Results and Discussion}

Since the $\mathrm{NO}_{\mathrm{x}}$ emissions for the 5-recess and flat dome configurations were reported previously, ${ }^{2}$ this paper focuses on the 9-recess configuration.

\section{A. Effect of fuel staging}

A given adiabatic flame temperature - based on the combustor inlet conditions and the total fuel and air flow - can be achieved with multiple ways. For example, all fuel stages can have the same local equivalence ratio, "equal staging", or some fuel stages can be slightly richer than the local equivalence ratio and other 


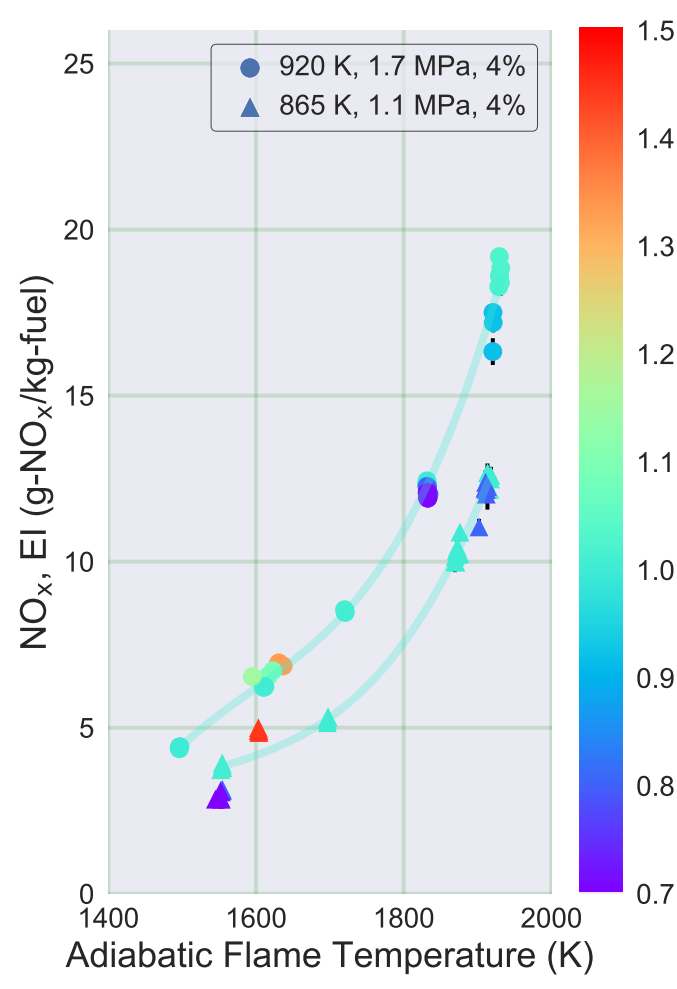

(a)

1.5

1.4

1.3

1.2

0.9

0.8

0.7
0

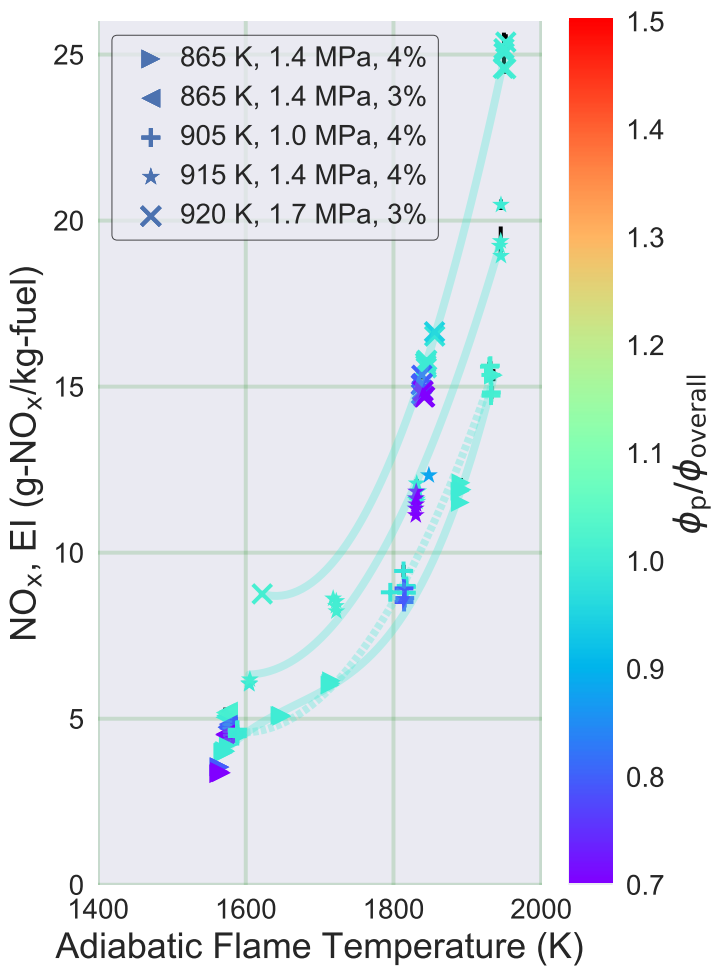

(b)

Figure 4: Effect of fuel staging on high power $N O_{x}$ emissions for the 9-recess configuration, showing (a) inlet conditions with more than one alternative fuel staging and (b inlet conditions with only one alternative fuel staging. 
stages slightly leaner. If all stages mix the fuel and air equally well and produce the same amount of $\mathrm{NO}_{\mathrm{x}}$, the lowest $\mathrm{NO}_{\mathrm{x}}$ emissions would occur with equal staging. For this reason, most testing was done with equal staging. However, at a subset of points, the fuel staging was varied. The pilot was made slightly leaner (richer) and the three main stages were then made very slightly richer (leaner) to maintain the overall equivalence ratio.

Figure 4 shows the effect of fuel staging on $\mathrm{NO}_{\mathrm{x}}$ emissions for the 9-recess configuration at high power conditions. Decreasing pilot equivalence ratio by up to $30 \%$ relative to the overall equivalence ratio tended to decrease $\mathrm{NO}_{\mathrm{x}}$ emissions slightly, by $1 \mathrm{~g} / \mathrm{kg}$ or less. This decrease in $\mathrm{NO}_{\mathrm{x}}$ emissions tended to lessen as the adiabatic flame temperature increased. Increasing the relative equivalence ratio of the pilot tended to increase $\mathrm{NO}_{\mathrm{x}}$ emissions, again by $1 \mathrm{~g} / \mathrm{kg}$ or less. To minimize $\mathrm{NO}_{\mathrm{x}}$ emissions, either the pilot design should be changed or the pilot should be run slightly leaner than the overall equivalence ratio. Since the pilot fuel-air mixer was designed to maximize low power combustion efficiency and minimize the equivalence ratio at lean blowout, running the pilot slightly leaner is probably the best choice.

\section{B. Emissions with minimal or no fuel staging}

$\mathrm{NO}_{\mathrm{x}}$ emissions with little or no fuel staging are shown in Figure 5. The top row shows data taken at similar inlet pressures but varying inlet pressures, and the bottom rows shows data taken at similar inlet temperatures but varying inlet temperatures. The first row also shows data for the 5 -recess and flat dome configurations, for comparison purposes.

Emissions results show that the 9-recess configuration has higher $\mathrm{NO}_{\mathrm{x}}$ emissions than the other two configurations. This can be seen by comparing the emissions at flame temperatures near $860 \mathrm{~K}$ (orange symbols) and $645 \mathrm{~K}$ (blue symbols). Near $860 \mathrm{~K}$, the 9-recess configuration has higher $\mathrm{NO}_{\mathrm{x}}$ emissions than the flat dome configuration at flame temperatures above $1600 \mathrm{~K}$. Due to flametube limitations during 5recess testing, this configuration was not evaluated at $860 \mathrm{~K}$, but previous results near $810 \mathrm{~K}$ showed that the 5-recess configuration generally had higher $\mathrm{NO}_{\mathrm{x}}$ emissions than the flat dome configuration. ${ }^{2}$ At $645 \mathrm{~K}$, the 9-recess $\mathrm{NO}_{\mathrm{x}}$ emissions were higher than those for the 5 -recess or flat dome configurations, even if $1 \mathrm{~g} / \mathrm{kg}$ of $\mathrm{NO}_{\mathrm{x}}$ is subtracted from the 9-recess configuration due to unequal fuel staging.

\section{Combustion efficiency}

\section{High power operation}

The high power $\left(\mathrm{T}_{3}>655 \mathrm{~K}\right) \mathrm{CO}$ emissions and combustion efficiency are shown in Figure 6 . All three configurations have similar CO emissions and combustion efficiency, with points for all three configurations falling on nearly the same curve. The $\mathrm{CO}$ emissions and combustion efficiency may be slightly worse for the 9 -recess configuration, but the difference is small.

Figure 6a,b suggests that the $\mathrm{CO}$ emissions are primarily due to equilibrium $\mathrm{CO}$ concentration and not to incomplete combustion. First, the $\mathrm{CO}$ emissions seem to be primarily a function of adiabatic flame temperature. Neither the combustor inlet temperature $(655-922 \mathrm{~K})$ and pressure (1.0-1.8 $\mathrm{MPa}$ ) nor the configuration seems to have a major effect on $\mathrm{CO}$ emissions. This is what would be expected of equilibrium $\mathrm{CO}$ emissions. Second, the CO concentration increases with flame temperature. If CO emissions were caused by combustion inefficiency, they would typically decrease with increasing flame temperature, especially for fuel-lean combustion, which has excess oxygen.

Therefore, the equilibrium CO concentration was calculated using CEA and the results plotted in Figure 7. For all three configurations, the measured $\mathrm{CO}$ is near to the equilibrium $\mathrm{CO}$ at all inlet temperatures and pressures and for all configurations. However, compared to the equilibrium $\mathrm{CO}$, the $\mathrm{CO}$ emissions do seem to be slightly higher for the 9-recess configuration.

Much of the equilibrium $\mathrm{CO}$ would oxidize in an actual engine as the combustion products move through the (lower temperature) turbine and nozzle. Thus, the combustion efficiency can be corrected for equilibrium CO concentration. This increases the combustion efficiency to $99.99 \%$ and above, as shown in Figure 6c.

\section{Low power operation}

Emissions at low power conditions are shown in Figures 8 and 9. Since control of fuel staging is critical for low power operation and since the 9-recess configuration was the only configuration where all the fuel flow for all four stages could be varied independently, only results for the 9-recess configuration are shown. 


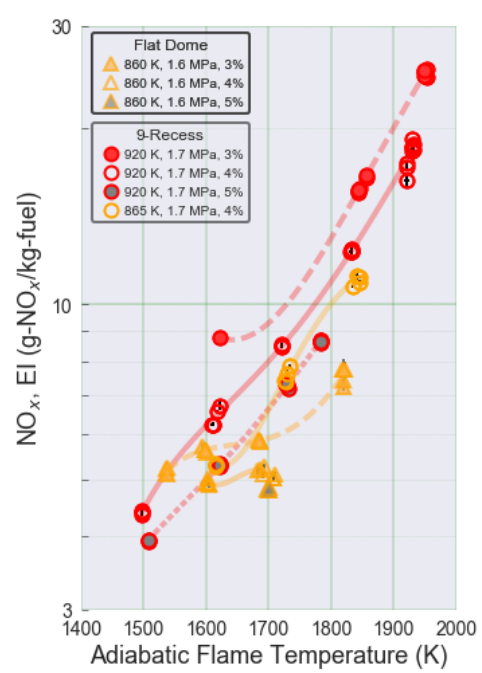

(a)

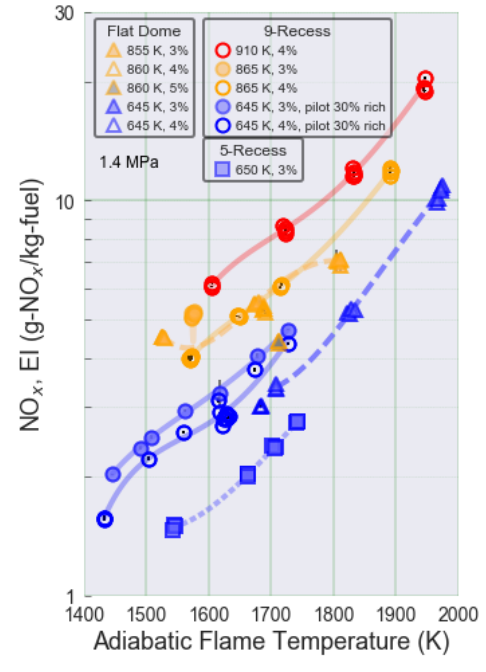

(b)

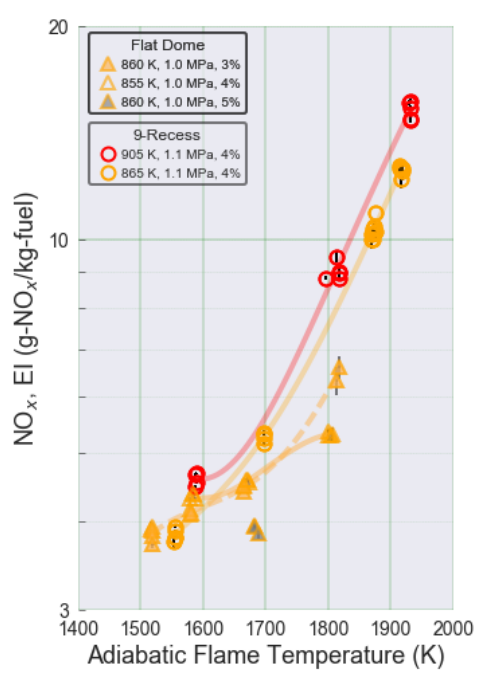

(c)

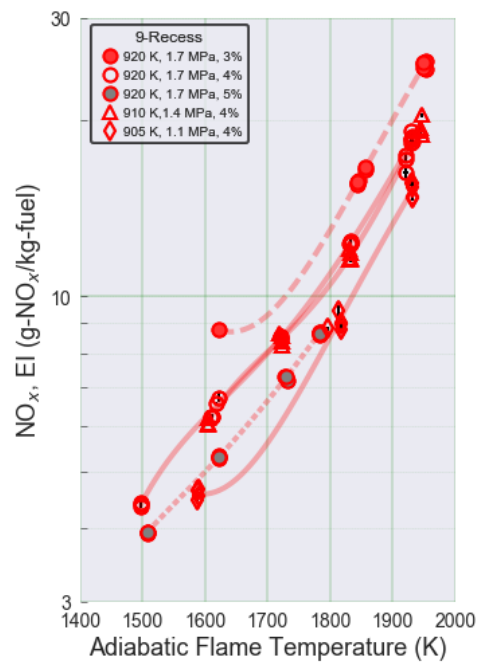

(d)

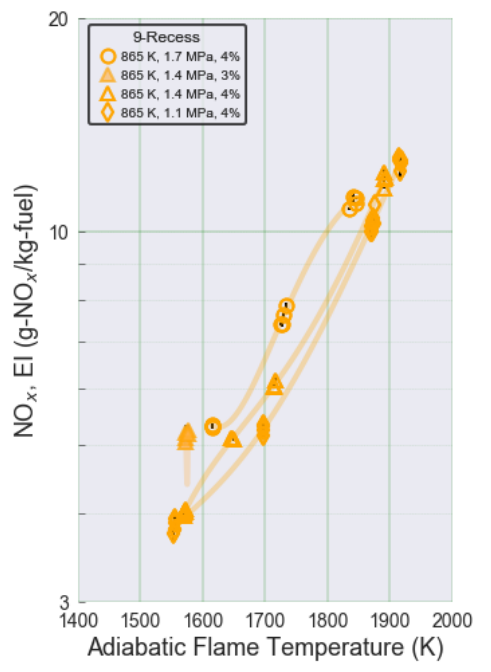

(e)

Figure 5: $\mathrm{NO}_{x}$ emissions at various combustor inlet conditions. Note that the the caption "pilot $30 \%$ rich" in the legend in (b) means that the pilot equivalence ratio is $30 \%$ richer than the overall equivalence ratio, not that the pilot is rich overall (it is lean). 


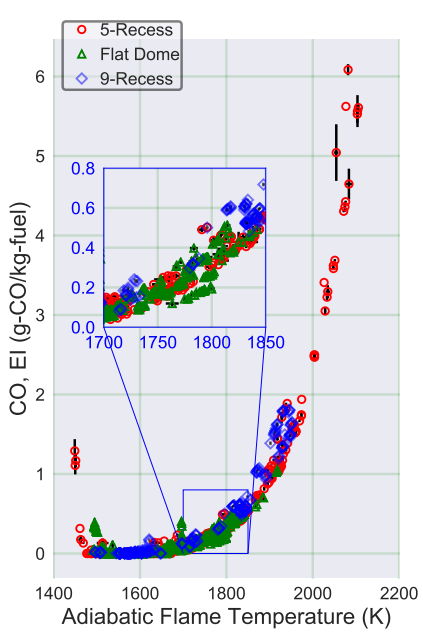

(a)

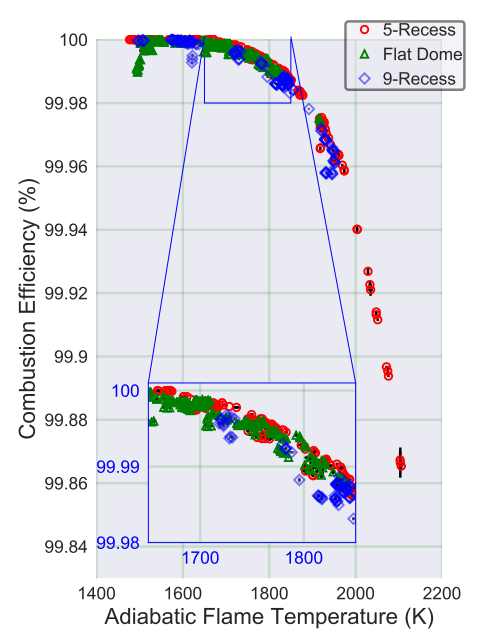

(b)

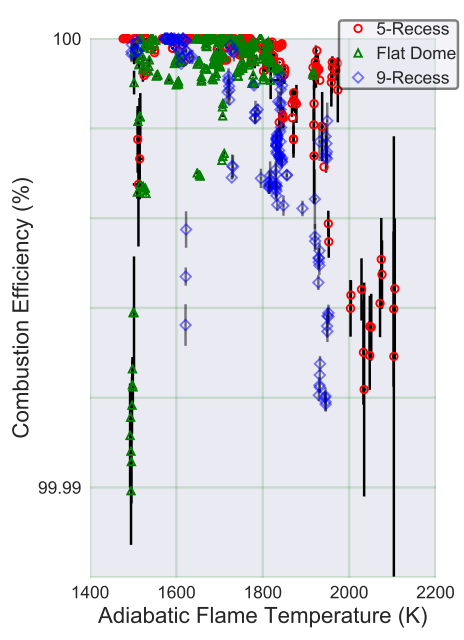

(c)

Figure 6: High power $\left(T_{3}>655 \mathrm{~K}\right)$ : (a) carbon monoxide emissions and (b,c) combustion efficiency (b) with no correction for equilibrium $C O$ and (c) with correction for equilibrium $C O$. Note the difference in scale between (b) and (c). Also note that the size of the markers is a function of inlet temperature.

Figure 8 shows $\mathrm{NO}_{\mathrm{x}}$ and $\mathrm{CO}$ emissions as a function of flametube combusted gas temperature at a range of low power (30\% and below) inlet conditions. The inlet conditions are not shown on separate curves because many of the conditions are on the proprietary PW N+2 ICAO cycle. Unlike 6 , where a single adiabatic flame temperature often resulted from multiple $(\phi$, inlet temperature, inlet pressure) combinations, in Figure 8 the highest combusted gas temperatures correspond to the conditions closer to $30 \%$ power (inlet pressure in the 1.4 MPa range and inlet temperature in the $650 \mathrm{~K}$ range) and the lowest combusted gas temperatures correspond to conditions closer to the $7 \%$ power condition (inlet pressure in the $0.7 \mathrm{MPa}$ range and inlet temperature in the $525 \mathrm{~K}$ range).

At the cost of increased $\mathrm{NO}_{\mathrm{x}}$ emissions, fuel staging can be used to substantially increase the operating range and combustion efficiency of the second-generation LDI configurations. At low power conditions, CO emissions increase and combustion efficiency decreases with decreasing (local) flame temperature. At first, this decrease in combustion efficiency is gradual, but at a certain point there is a rapid drop in combustion efficiency.With all fuel stages on, this rapid drop occurs with combusted gas temperatures between 1500 $\mathrm{K}$ and $1400 \mathrm{~K}$. This is similar to the results from first-generation SV-LDI, with and without fuel staging. ${ }^{1}$ However, unlike with first-generation SV-LDI, with second-generation LDI fuel staging successfully increases the operating range and combustion efficiency by allowing the overall combusted gas temperature to decrease while keeping the local flame temperature high. At a combusted gas temperature of $1400 \mathrm{~K}$, turning main stages 2 and 3 off increases the combustion efficiency from $98 \%$ to above $99.5 \%$. With only the pilot and main stage 1 on, the combustion efficiency decreases gradually until about $1200 \mathrm{~K}$. Between $1200 \mathrm{~K}$ and $1100 \mathrm{~K}$, the combustion efficiency rapidly drops from $98.5 \%$ to $96.5 \%$. However, turning main stage 1 off i.e., pilot-only operation - increases the combustion efficiency at $1100 \mathrm{~K}$ back to $98.5 \%$.

Figure 9 shows emissions and combustor efficiency for the $7 \%$ ICAO point on the NASA N+3 small-core cycle $^{\mathrm{a}}$. For this point, only the pilot stage was fueled. The right side of the figure shows points at equivalence ratios at and above the $7 \%$ condition. For these points, data was taken only after the fuel flow and emissions were stabilized. At equivalence ratios below the 7\% ICAO point, fuel was continuously decreased until lean blowoff at a $\phi$ between 0.04 and 0.05 . At equivalence ratios below the ICAO $7 \%$ point, fuel was continuously decreased until lean blowoff at a $\phi$ between 0.04 and 0.05 . At the ICAO $7 \%$ point, $\mathrm{NO}_{\mathrm{x}}$ emissions are 3.6 $\mathrm{g} / \mathrm{kg}$, which is good. The combustion efficiency was $97 \%$; this is much better than first-generation LDI designs but is lower than the desired $99+\%$ combustion efficiency at the $7 \%$ ICAO point. Lean blowoff takes place at an equivalence ratio of less than half of the nominal $7 \%$ point, which is a good margin. Near lean blowoff, $\mathrm{NO}_{\mathrm{x}}$ emissions are $2.3 \mathrm{~g} / \mathrm{kg}$ and combustion efficiency is $90.6 \%$.

\footnotetext{
${ }^{a}$ Since the combustor inlet temperature was inadvertently varied by $12 \mathrm{~K}$ while we were taking this point, it is also shown.
} 


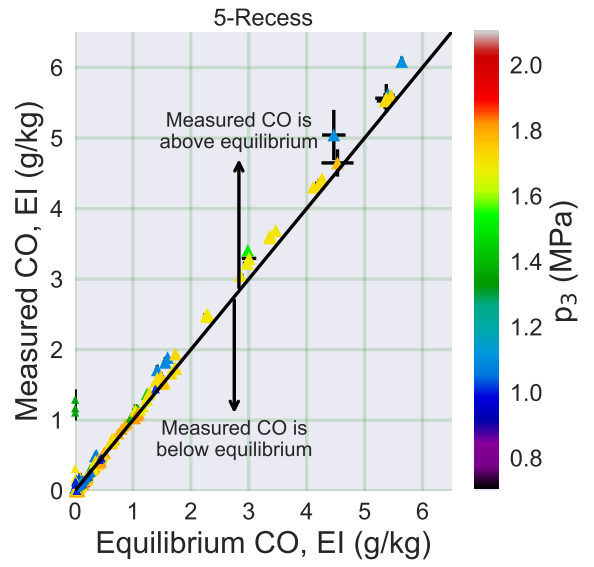

(a)

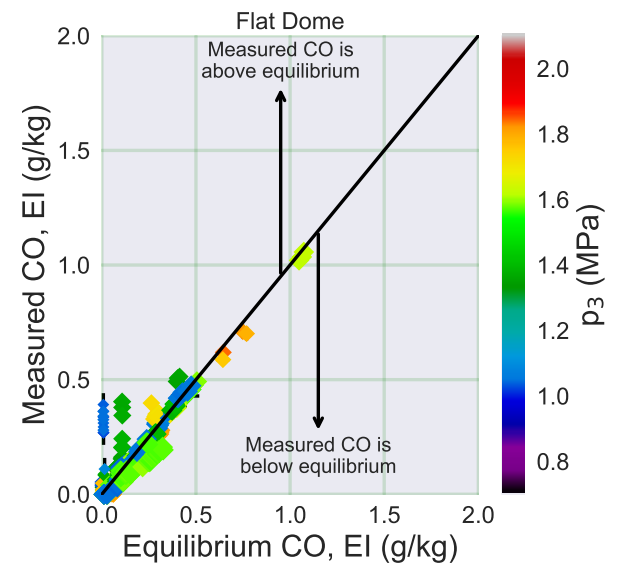

(c)

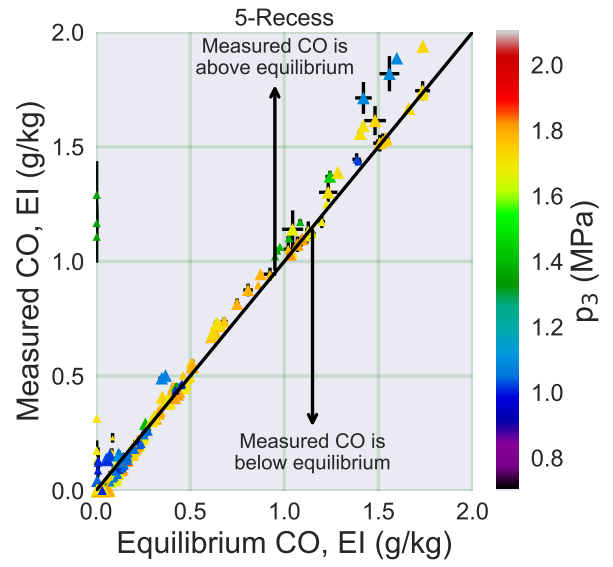

(b)

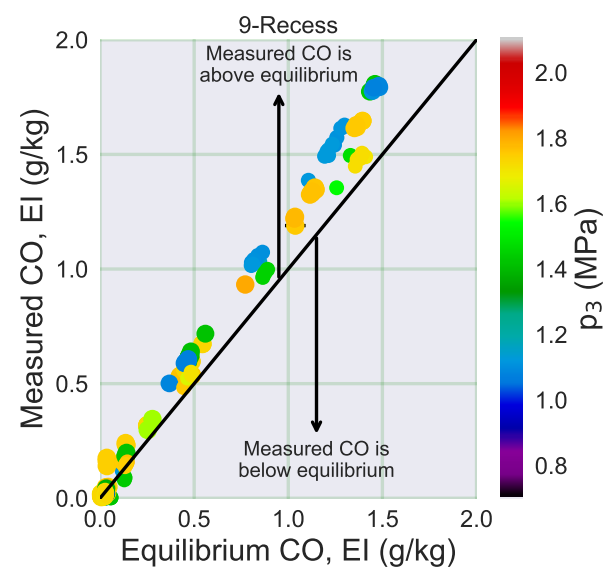

(d)

Figure 7: High power $\left(T_{3}>655 \mathrm{~K}\right)$ : Comparison of measured and equilibrium CO for the (a, b) 5-recess, (c) flat dome, and (d) 9-recess configurations. Note the larger scale for (a). 


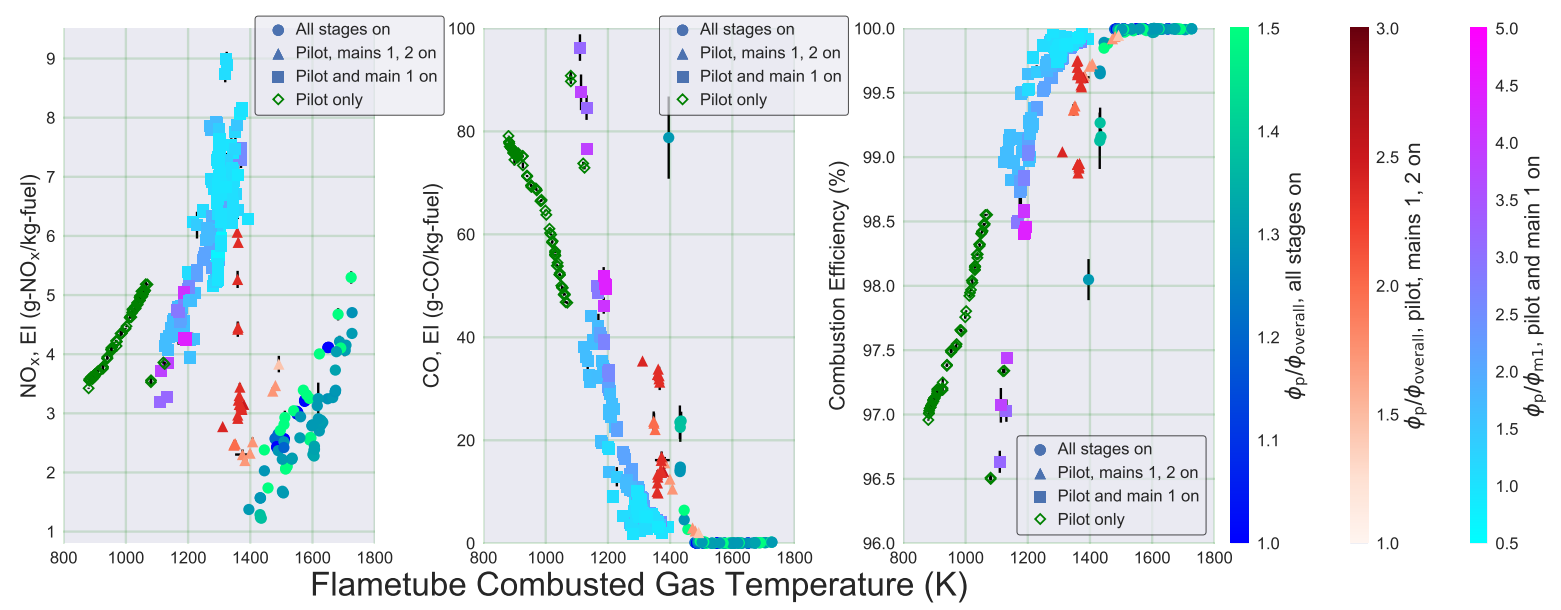

Figure 8: Low power $\left(475 \mathrm{~K}<T_{3}<655 \mathrm{~K}\right.$ ): (left) $N O_{x}$ emissions, (middle) carbon monoxide emissions, and (right) combustion efficiency for the 9-recess configuration. As the adiabatic flame temperature and equivalence ratio decreased, the fuel staging changed: the ratio of the pilot equivalence ratio to the overall equivalence ratio was increased first by changing the fuel splits and then by successively turning off the main stages.

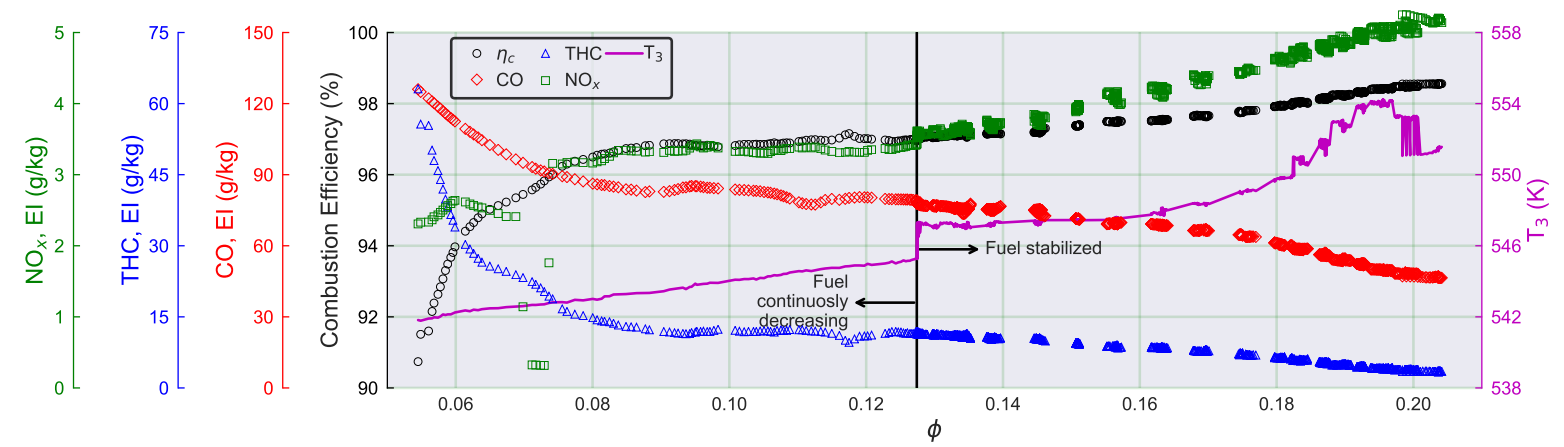

Figure 9: Performance of the 9-recess configuration at the $7 \%$ ICAO point on the NASA N+3 cycle. The vertical line indicates the equivalence ratio of the $7 \%$ ICAO point. 
Table 3: Coefficients for correlation equations. The values for the flat dome configuration are taken from Tacina et al. ${ }^{2}$

\begin{tabular}{lcccccccc}
\hline Configuration & Fit & $a_{p}$ & $b_{p}$ & $a_{m 1}$ & $b_{m 1}$ & $a_{m 23}$ & $b_{m 23}$ & $\mathrm{R}^{2}$ \\
\hline Flat Dome & Fit 1n & 0.0081 & 0.290 & 0.350 & 7.15 & 0.184 & 7.37 & 0.950 \\
Flat Dome & Fit 2n & 0.0024 & 0.453 & 0.0958 & 7.56 & 0.095 & 8.04 & 0.926 \\
9-Recess & Fit 1n & 0.0602 & 0.379 & 0.0525 & 3.34 & 0.256 & 6.98 & 0.934 \\
9-Recess & Fit 2n & 0.00272 & 1.02 & 0.176 & 3.45 & 0.0720 & 8.13 & 0.966 \\
\hline
\end{tabular}

\section{D. $\mathrm{NO}_{\mathrm{x}}$ correlation equations}

Since the CE- 5 facility cannot reach the pressures for the $100 \%$ and $85 \%$ ICAO points, correlation equations were developed for high power $\mathrm{NO}_{\mathrm{x}}$ emissions. The form of the correlation equations is based on the correlation equations developed for first-generation SV-LDI $\mathrm{NO}_{\mathrm{x}}$ emissions in Tacina et al. ${ }^{1}$

A successful correlation equation must take into account the difference in fuel-air mixers between stages. ${ }^{2}$ The $\mathrm{NO}_{\mathrm{x}}$ emissions for a simplex stage are significantly different those from an airblast stage. ${ }^{9,10}$ This is illustrated in Figure 10, reproduced from Tacina et al. ${ }^{9}$ Although the conditions are not typical - the equivalence ratio is double to triple a typical value for that temperature and pressure and was chosen to produce combustion dynamics - it clearly shows that $\mathrm{NO}_{\mathrm{x}}$ emissions from the simplex main 1 stage are significantly higher than those from the airblast main 2 stage.

Therefore, the correlation equations contain terms for each stage. The main 2 and main 3 stages are grouped together because (1) the fuel-air mixers are geometrically similar (identical fuel injector types and air swirler angles) and (2) they were typically at the same local fuel-air ratio, making it numerically difficult to obtain independent correlation equation coefficients.

Two forms of the correlation equations were developed:

$$
\begin{aligned}
& \text { Fit 1n: } \quad \mathrm{EI}-\mathrm{NO}_{\mathrm{x}}=p_{3}^{0.50} e^{T_{3} / 230}\left(\frac{\Delta p}{p}\right)^{-0.60}\left[a_{p} \phi_{p}^{b_{p}}+a_{m 1} \phi_{m 1}^{b_{m 1}}+a_{m 23}\left(\phi_{m 2}^{b_{m 23}}+\phi_{m 3}^{b_{m 23}}\right)\right] \\
& \text { Fit 2n: } \quad \mathrm{EI}-\mathrm{NO}_{\mathrm{x}}=p_{3}^{0.59} e^{T_{3} / 194}\left(\frac{\Delta p}{p}\right)^{-0.56}\left[a_{p} \phi_{p}^{b_{p}}+a_{m 1} \phi_{m 1}^{b_{m 1}}+a_{m 23}\left(\phi_{m 2}^{b_{m 23}}+\phi_{m 3}^{b_{m 23}}\right)\right],
\end{aligned}
$$

with $\mathrm{p}_{3}$ in $\mathrm{kPa}, \mathrm{T}_{3}$ in $\mathrm{K}$, and $\frac{\Delta p}{p}$ in $\%$. The fixed parameters (exponents on $\mathrm{p}_{3}$ and $\Delta p$ and divisor of $\mathrm{T}_{3}$ ) are taken from the correlation equations developed from the first-generation SV-LDI configuration. ${ }^{1}$ The coefficients $a_{i}, b_{i}$ are given in Table 3 and the measured $\mathrm{NO}_{\mathrm{x}}$ emissions are plotted against the values calculated from the correlation equations in Figure 11. The correlation equations describe the data reasonably well, with $R^{2}$ values above 0.90 .

The correlation equations were used to estimate the ICAO $\mathrm{NO}_{\mathrm{x}}$ emissions. For the Pratt \& Whitney $\mathrm{N}+2$ cycle, the flat dome landing-takeoff $\mathrm{NO}_{\mathrm{x}}$ is estimated to be $87-88 \%$ below the CAEP/ 6 standards, and the 9-recess landing-takeoff $\mathrm{NO}_{\mathrm{x}}$ is estimated to be between 81 and $85 \%$ below the CAEP/ 6 standards. For the NASA N+3 cycle, the 9-recess landing-takeoff $\mathrm{NO}_{\mathrm{x}}$ is estimated to be approximately $85 \%$ below the CAEP/ 6 standards. These estimated $\mathrm{NO}_{\mathrm{x}}$ reductions exceed the ERA and AATT project goals of $75 \%$ reduction.

\section{Conclusions}

Three second-generation swirl-venturi lean direct injection (SV-LDI) combustor configurations were developed under the ERA project and tested under the ERA and AATT projects. Of the three configurations, the 5 -recess configuration had the lowest $\mathrm{NO}_{\mathrm{x}}$ emissions at high power conditions. The ICAO $\mathrm{NO}_{\mathrm{x}}$ emissions were estimated to be $81-88 \%$ below the CAEP/ 6 standards, exceeding the project goals of $75 \%$ reduction. 

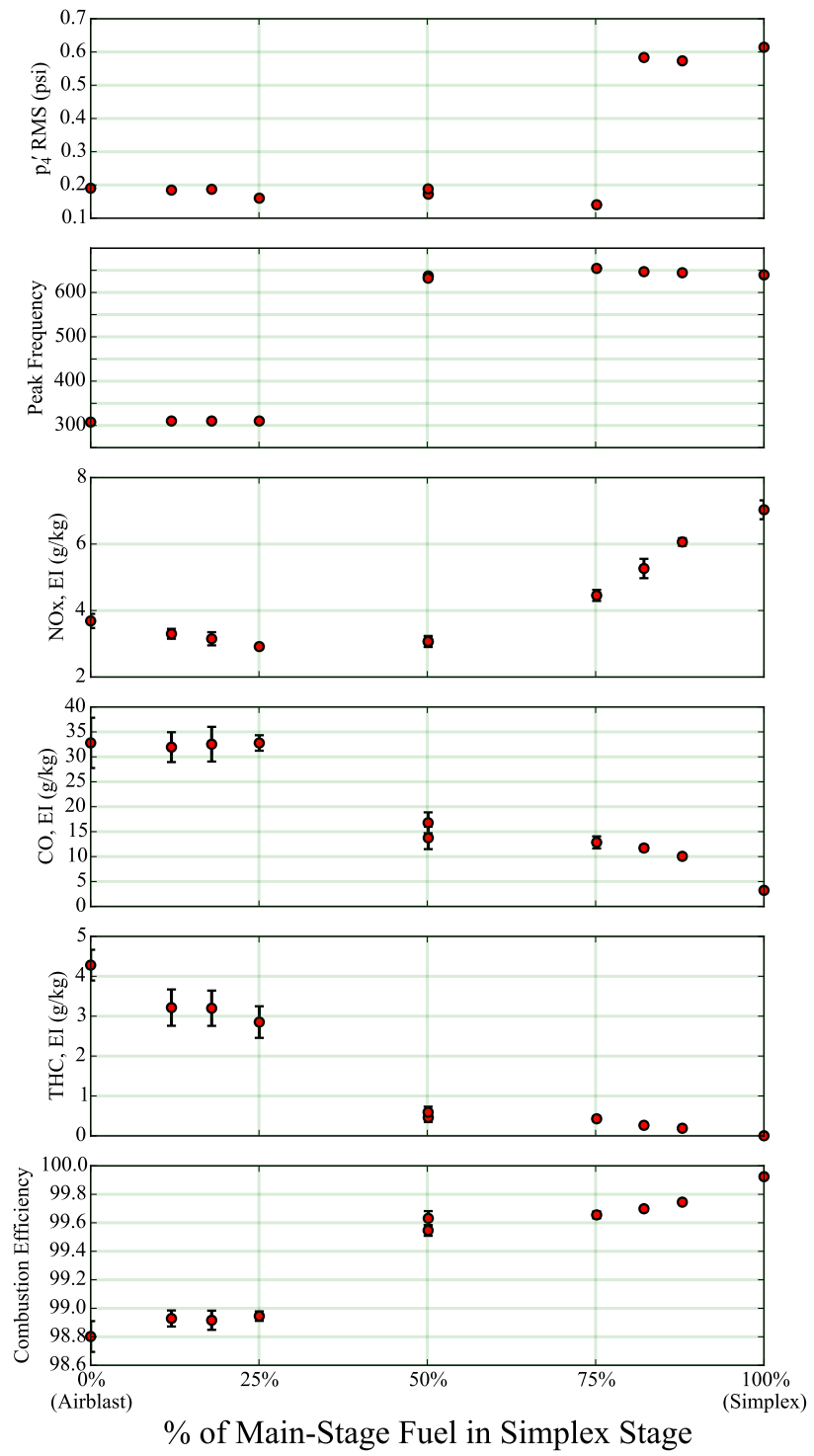

Figure 10: Effect of fuel staging on gaseous emissions and combustion dynamics at $450 \mathrm{~F}$ and 100 psia and an overall equivalence ratio of 0.35 for the 9-recess configuration. The pilot fuel flow is keep fixed and the main fuel is split between the simplex main-1 stage and the airblast main-2 stage. Reproduced from Tacina et al. ${ }^{9}$ 


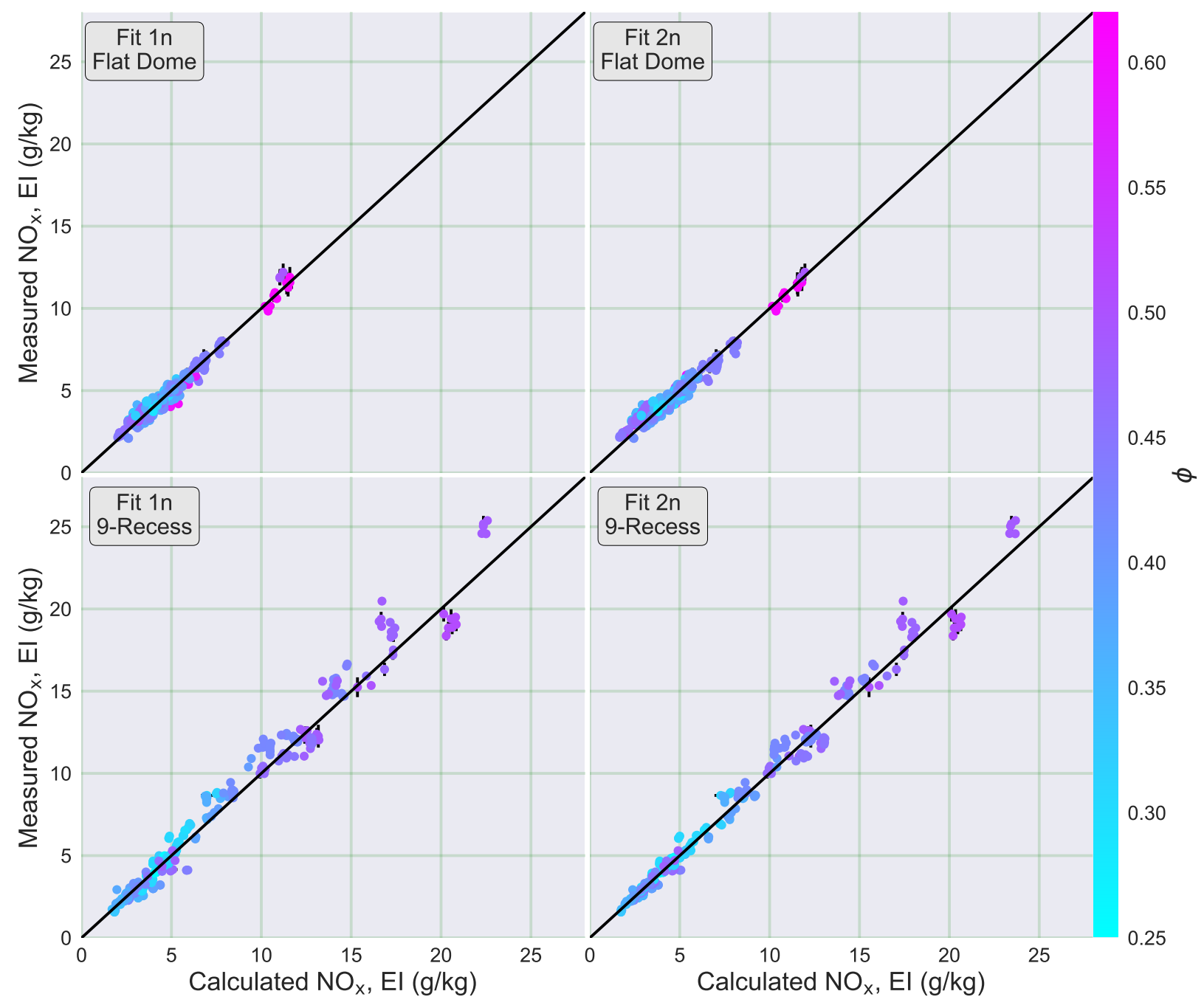

Figure 11: $N O_{x}$ correlation equations for the flat dome and 9-recess configurations. 


\section{Acknowledgments}

This work was supported by the Environmentally Responsible Aviation (ERA) and Advanced Air Transport Technology projects.

Thanks to the CE-5 crew.

\section{References}

${ }^{1}$ Tacina, R., Lee, P., and Wey, C., "A Lean-Direct-Injection Combustor Using a 9 Point Swirl-Venturi Fuel Injector," ISABE-2005-1106, 2005.

${ }^{2}$ Tacina, K. M., Lee, P., Mongia, H., Chang, C. T., He, Z., and Dam, B., "A Second Generation Swirl-Venturi Lean Direct Injection Combustion Concept," AIAA 2014-3434, 2014.

${ }^{3}$ Heath, C. M., Hicks, Y. R., Anderson, R. C., and Locke, R. J., "Optical Characterization of a Multipoint Lean Direct Injector for Gas Turbine Combustors :Velocity and Fuel Drop Size Measurements," GT2010-22960, 2010.

${ }^{4}$ Hicks, Y. R., Heath, C. M., Anderson, R. C., and Tacina, K. M., "Investigations of a combustor using a 9-point swirlventuri fuel injector: recent experimental results." ISABE-2011-1106, 2011.

${ }^{5}$ SAE E-31 Technical Committee, "Procedure for the Continuous Sampling and Measurement of Gaseous Emissions from Aircraft Turbine Engines," SAE ARP 1256D, 2011.

${ }^{6}$ SAE E-31 Technical Committee, "Procedure for the Analysis and Evaluation of Gaseous Emissions from Aircraft Engines," SAE ARP 1533B, 2013.

${ }^{7}$ McBride, B. and Gordon, S., "Computer Program for Calculating and Fitting Thermodynamic Functions," NASA RP1271,1992

${ }^{8}$ McBride, B., Zehe, M., and Gordon, S., "NASA Glenn Coefficients for Calculating Thermodynamic Properties of Individual Species," NASA TP-3287, 1993.

${ }^{9}$ Tacina, K. M., Lee, P., Chang, C., He, Z., Dam, B., and Podboy, D., "An assessment of combustion dynamics in a low- $\mathrm{NO}_{x}$ second-generation swirl-venturi lean direct injection combustion concept," ISABE-2015-20249, 2015.

${ }^{10}$ Ajmani, K., Mongia, H., and Lee, P., "CFD Computations of Emissions For LDI-2 Combustors with Simplex and Airblast Injectors," AIAA 2014-3529, 2014. 